\title{
Increased D-alanylation of lipoteichoic acid and a thickened septum are main determinants in the nisin resistance mechanism of Lactococcus lactis
}

\begin{abstract}
Correspondence
Oscar P. Kuipers

o.p.kuipers@rug.nl
\end{abstract}

Received 27 November 2007

Revised 1 February 2008

Accepted 22 February 2008

\author{
Naomi E. Kramer, ${ }^{1,2}$ Hester E. Hasper, ${ }^{2}$ Patrick T. C. van den Bogaard, ${ }^{3}$ \\ Siegfried Morath, ${ }^{4}$ Ben de Kruijff, ${ }^{2}$ Thomas Hartung, ${ }^{4}$ Eddy J. Smid, ${ }^{5}$ \\ Eefjan Breukink, ${ }^{2}$ Jan Kok ${ }^{1}$ and Oscar P. Kuipers ${ }^{1}$ \\ ${ }^{1}$ Molecular Genetics Group, Groningen Biomolecular Sciences and Biotechnology Institute, \\ University of Groningen, PO Box 14, 9750 AA Haren, The Netherlands \\ ${ }^{2}$ Department of Biochemistry of Membranes, Center for Biomembranes and Lipid Enzymology, \\ Institute of Biomembranes, Utrecht University, Padualaan 8, $3584 \mathrm{CH}$ Utrecht, The Netherlands \\ ${ }^{3}$ Eukaryotic Microbiology, Groningen Biomolecular Sciences and Biotechnology Institute, University \\ of Groningen, PO Box 14, 9750 AA Haren, The Netherlands \\ ${ }^{4}$ European Commission, Joint Research Centre, IHCP, European Centre for the Validation of \\ Alternative Methods, 21020 Ispra, Italy \\ ${ }^{5}$ NIZO Food Research, Flavour and Natural Ingredients Section, PO Box 20, 6710 BA Ede, The \\ Netherlands
}

\begin{abstract}
Nisin is a post-translationally modified antimicrobial peptide produced by Lactococcus lactis which binds to lipid II in the membrane to form pores and inhibit cell-wall synthesis. A nisinresistant $\left(\mathrm{Nis}^{\mathrm{R}}\right)$ strain of $L$. lactis, which is able to grow at a 75 -fold higher nisin concentration than its parent strain, was investigated with respect to changes in the cell wall. Direct binding studies demonstrated that less nisin was able to bind to lipid II in the membranes of L. lactis Nis ${ }^{R}$ than in the parent strain. In contrast to vancomycin binding, which showed ring-like binding, nisin was observed to bind in patches close to cell-division sites in both the wild-type and the $\mathrm{Nis}^{\mathrm{R}}$ strains. Comparison of modifications in lipoteichoic acid of the $L$. lactis strains revealed an increase in D-alanyl esters and galactose as substituents in L. lactis $\mathrm{Nis}^{\mathrm{R}}$, resulting in a less negatively charged cell wall. Moreover, the cell wall displays significantly increased thickness at the septum. These results indicate that shielding the membrane and thus the lipid II molecule, thereby decreasing abduction of lipid II and subsequent pore-formation, is a major defence mechanism of $L$. lactis against nisin.
\end{abstract}

\section{INTRODUCTION}

Lactococcus lactis is a lactic acid bacterium (LAB) that is of major importance in the food industry. Some LAB produce agents that are capable of inhibiting the growth of a wide variety of food spoilage bacteria, for example by the excretion of antimicrobial peptides or bacteriocins. One of the best-studied antimicrobials is nisin (Sahl \& Bierbaum, 1998). Nisin, a positively charged lantibiotic produced by L. lactis, and nisin-producing strains have been used as food preservatives for a long time, especially in dairy products (Delves-Broughton et al., 1996; Hurst, 1981; Mattick \& Hirsch, 1944). Nisin displays a broad spectrum of activity against Gram-positive bacteria (Jung, 1991) and

Abbreviations: LTA, lipoteichoic acid; WTA, wall teichoic acid.

NMR spectra are available with the online version of this paper. kills bacteria by inhibiting cell-wall biosynthesis and by forming pores in the cytoplasmic membrane, both initiated by binding to lipid II (Breukink et al., 1999; Brötz et al., 1998). Multiple molecules in the lipid II-nisin complex aggregate to form a pore (Hasper et al., 2004). Recently, it has been reported that nisin, as well as some non-poreforming lantibiotics are also able to abduct lipid II from major sites of cell-wall biosynthesis, providing another mechanism of cell killing (Hasper et al., 2006). Insights into the molecular mechanisms by which bacteria develop nisin resistance and the basis of the large differences in nisin sensitivity observed among wild-type bacterial species is of major importance for future antimicrobial applications of nisin or nisin variants.

It has been reported that the lipid II content in the cytoplasmic membrane of bacteria and their nisin 
sensitivity are not correlated, but that resistance is a combined result of changes in the cell wall that hamper nisin from reaching lipid II (Kramer et al., 2004). The cell wall in Gram-positive bacteria consists of a relatively thick, multi-layered peptidoglycan sacculus that, depending on the bacterial species, may contain proteins, lipoteichoic acid (LTA), wall teichoic acid (WTA) and polysaccharides. Notably, not all Gram-positive bacteria harbour LTA or WTA. The cell wall has a net negative charge, mainly because of the LTA and WTA content. LTA in its most common form consists of a polyglycerol phosphate that is linked to the membrane via a glycolipid anchor. Alternatively, a polyribitol phosphate may form the LTA core, but other polyols such as mannitol, erythritol or arabitol can be present (Naumova et al., 2001). Some bacteria do not possess LTA, but have other anionic polymers such as teichuronic acid. LTA can contain various glycosyl substituents, such as an $\mathrm{OH}$ group, Dalanyl moieties, $\alpha$-GlcNAc or $\alpha$-galactose (Delcour et al., 1999). In Gram-positive bacteria, four proteins, encoded by the dlt operon, are required for the synthesis of D-alanyl esters for substitution in LTA, which results in positive charges being incorporated into the mostly negatively charged cell wall (Delcour et al., 1999; Peschel et al., 1999). To date, it is not known whether or not L. lactis contains WTA. Three functions of D-alanyl teichoic acids have been proposed so far, namely (i) preventing the binding of autolysins (Steen et al., 2003), (ii) maintaining cation homeostasis, and (iii) defining the electrochemical properties of the cell wall (Heaton \& Neuhaus, 1993).

LTA has been shown to play an important role in nisin resistance in Staphylococcus aureus and Streptococcus bovis; however, the exact LTA composition of these strains has not been analysed. A Staphylococcus aureus strain containing several copies of the dlt operon is less sensitive to various antimicrobial peptides, including nisin (Peschel et al., 1999). Nisin-resistant $\left(\mathrm{Nis}^{\mathrm{R}}\right)$ cells of Streptococcus bovis harbour more LTA than nisin-sensitive cells (Mantovani \& Russell, 2001). LTA alanylation also seems to affect the susceptibility of Streptococcus pneumoniae to nisin (Kovacs et al., 2006). We have shown previously that the cell wall of Gram-positive bacteria can be a barrier for nisin to reach lipid II, since protoplasts of a $\mathrm{Nis}^{\mathrm{R}}$ strain of Micrococcus flavus were almost as sensitive to nisin as protoplasts of the parent strain (Kramer et al., 2004). However, the LTA of the $\mathrm{Nis}^{\mathrm{R}}$ strains has not been isolated in any of these studies, nor have the molecular changes in LTA been reported to be involved in the nisin resistance mechanism.

A transcriptome analysis study has shown that the expression of various genes involved in four possible mechanisms was changed in a L. lactis $\mathrm{Nis}^{\mathrm{R}}$ strain compared to the wild-type (Kramer et al., 2006), based on the following observations. (i) Genes involved in cell-wall structure showed higher expression of the dlt and gal operons, resulting in a changed LTA structure. GalE, encoded by the gal operon in L. lactis subsp. cremoris (Grossiord et al., 2003), is involved in galactose substitution in LTA. $p b p 2 A$ was also more highly expressed. There was also (ii) a difference in the expression of $A B C$ transporters, (iii) a difference in the expression of genes involved in the saturation and elongation of fatty acids, and (iv) changes in the expression of genes possibly controlling the $\mathrm{pH}$ on the outer side of the membrane, preventing nisin binding to lipid II (Kramer et al., 2006). However, the biochemical changes in membrane and cell wall were not further investigated in this study.

Since earlier studies have indicated that several genes involved in cell-wall synthesis contribute to nisin resistance (Kramer et al., 2006), and do not influence the total lipid II content, we set out to further investigate the role of the cell wall in nisin resistance. Our results point to a combination of two major mechanisms to effect nisin resistance: elevating the net charge of the cell wall concomitantly with increasing the thickness of the septum, where the majority of the lipid II molecules reside. Both strategies effectively hamper binding of nisin to lipid II molecules in the bacterial cytoplasmic membrane, preventing abduction of lipid II from sites of cell-wall synthesis and preventing cell lysis by pore formation.

\section{METHODS}

Bacterial strains, growth conditions and MIC determinations. The strains used in this study were L. lactis IL1403 (Chopin et al., 1984), L. lactis IL1403 Nis ${ }^{\mathrm{R}}$ (Kramer et al., 2004) and L. lactis MG1363 $\Delta d l t D$ (Duwat et al., 1997). All strains were grown at $30{ }^{\circ} \mathrm{C}$ in $\mathrm{M} 17$ (Terzaghi \& Sandine, 1975) broth with $0.5 \%$ glucose (GM17) and antibiotics where appropriate (chloramphenicol, $5 \mu \mathrm{g} \mathrm{ml}^{-1}$; nisin, $3000 \mu \mathrm{g} \mathrm{l}^{-1}$, when using the $\mathrm{Nis}^{\mathrm{R}}$ strain of L. lactis). GM17 plates contained $1.5 \%$ agar. The MIC was determined as described previously (Kramer et al., 2004).

Isolation of a $\mathbf{N i s}^{\mathbf{R}}$ variant of $\boldsymbol{L}$. lactis IL1403. A nisin stock solution was derived from nisaplin (2.5\% nisin; Aplin and Barrett) as described by Pol \& Smid (1999). A Nis ${ }^{\mathrm{R}}$ isogenic variant of L. lactis IL1403 was obtained as described previously (Kramer et al., 2004). This strain was used for all experiments.

LTA purification and structure analysis. LTA purification was performed by culturing 51 each of L. lactis IL1403, L. lactis IL1403 $\mathrm{Nis}^{\mathrm{R}}$ and L. lactis MG1363 $\Delta$ dltD overnight at $30{ }^{\circ} \mathrm{C}$ in $500 \mathrm{ml}$ flasks in GM17. Twenty grams (wet wt) of cells of each strain were harvested, resuspended in $60 \mathrm{ml} 0.1 \mathrm{M}$ sodium citrate buffer, $\mathrm{pH} 4.8$, and disrupted with a Branson sonifier (250 P5) three times for $5 \mathrm{~min}$ at an output level of 6 . Between every cycle the cells were kept on ice for $5 \mathrm{~min}$. LTA purification was done essentially as described previously (Morath et al., 2001). Briefly, the disrupted cells were mixed with $60 \mathrm{ml} n$-butanol (Merck), stirred for $30 \mathrm{~min}$ at room temperature and centrifuged at $13000 \mathrm{~g}$ for $40 \mathrm{~min}$ at room temperature. The centrifugation step was lengthened to obtain a higher yield of LTA. The aquatic phase was lyophilized, filtered using a $0.22 \mu \mathrm{m}$ NC 20/20 membrane filter (Schleicher and Schuell), resuspended in $5 \mathrm{ml}$ chromatography start buffer ( $15 \% \mathrm{n}$-propanol in $0.1 \mathrm{M}$ ammonium acetate, $\mathrm{pH}$. 4.7) and centrifuged at $45000 \mathrm{~g}$ for 15 min (Sorvall rotor, SS34) at room temperature. The supernatant was subjected to FPLC on octyl-Sepharose CL 4B (Amersham Pharmacia Biotech) with a $15-60 \%$ propanol gradient. The phosphor content of LTA was estimated according to the protocol of Rouser 
et al. (1970). NMR analysis was done at $600.13 \mathrm{MHz}\left({ }^{1} \mathrm{H}\right)$ and $300 \mathrm{~K}$, and was performed as described previously (Morath et al., 2001).

Electron microscopy. Overnight cultures of either L. lactis IL1403 or L. lactis IL1403 $\mathrm{Nis}^{\mathrm{R}}$ were harvested at room temperature by centrifugation for $1 \mathrm{~min}$ at $10000 \mathrm{~g}$. Cells were fixed in $3 \%$ glutaraldehyde in $0.1 \mathrm{M}$ sodium cacodylate buffer, pH. 7.2 (CAC), and kept on ice for $2 \mathrm{~h}$. Subsequently, the cells were washed three times in CAC, fixed in $1 \%$ osmium tetroxide and $5 \%$ potassium bichromate (1/1) in CAC at room temperature, and washed three times with MilliQ water. Contrast colouring was performed with $0.4 \%$ uranylacetate, and rehydration with a 100, 96, 70 and $50 \%$ ethanol solution series. The cells were embedded in Epon synthetic resin (Resolution Europe) and sliced on a cryo ultramicrotome (Reichert-Jung). The sliced cells were examined using a Philips CM10 electron microscope (FEI Company).

Subcellular localization of nisin and vancomycin at the L. lactis surface. Carboxyfluorescent-labelled nisin and vancomycin were isolated essentially as described previously (Hasper et al., 2006). A culture of L. lactis grown overnight was diluted $1: 30$ and grown under the appropriate growth conditions for about $3 \mathrm{~h}$ to an $\mathrm{OD}_{660}$ of about 0.8. Subsequently, fluorescein-labelled vancomycin $\left(1000 \mu \mathrm{g} \mathrm{l}^{-1}\right)$ or fluorescein-labelled nisin $\left(200 \mu \mathrm{g}^{-1}\right)$ was added to $0.5 \mathrm{ml}$ culture and the cells were incubated under the appropriate growth conditions for another $15 \mathrm{~min}$. The culture was centrifuged, then the cell pellet was washed in PBS (10 mM potassium phosphate, $\mathrm{pH} 7.5,150 \mathrm{mM} \mathrm{NaCl}$ ), fixed in $1.6 \%$ formaldehyde in PBS and kept on ice for $1 \mathrm{~h}$. After three washes in PBS, the cells were resuspended in PBS and an equal volume of $1 \%$ low-melting-point agar was added for fixation. Cells were inspected with a Zeiss confocal laser scanner (CLSM) 510 (excitation wavelength $488 \mathrm{~nm}$, detection between 500 and $550 \mathrm{~nm}$ ).

\section{RESULTS}

\section{Susceptibility testing of a $\mathbf{N i s}^{\mathrm{R}}$ variant of $\mathbf{L}$. lactis}

A Nis ${ }^{\mathrm{R}}$ variant of L. lactis IL1403 was used that was able to grow on media containing $3000 \mu \mathrm{g}$ nisin $\mathrm{l}^{-1}$, which is 75 times the MIC of the parental strain $\left(40 \mu \mathrm{g} \mathrm{l}^{-1}\right.$; Kramer et al., 2004). Vancomycin is another antimicrobial substance that inhibits cell-wall synthesis by binding to lipid II. This glycopeptide antibiotic binds to lipid II at the L-Lys-DAla-D-Ala terminus of the pentapeptide side chain (Sheldrick et al., 1978), but it does not make pores. Vancomycin can be used as an indicator of the location of lipid II in the cytoplasmic membrane of nisin-sensitive and nisin-resistant strains (Daniel \& Errington, 2003). However, as these authors also show, a significant proportion of the vancomycin $(\sim 50 \%)$ was bound to free D-Ala-D-Ala termini in the cell wall. It has been shown that the peptidoglycan layer of L. lactis contains a significant proportion of free D-Ala-D-Ala termini (25\% of intact pentapeptides; Courtin et al., 2006). Thus, vancomycin binding to free D-Ala-D-Ala termini will contribute significantly to the signal. Sensitivity to vancomycin was tested in the $\mathrm{Nis}^{\mathrm{R}}$ strain as well as in strain L. lactis MG1363 $\Delta d l t D$ which is five times more sensitive to nisin than the wild-type strain, probably due to changes in D-alanylation of LTA. No cross-resistance between nisin and vancomycin was observed in L. lactis
IL1403 $\mathrm{Nis}^{\mathrm{R}}$ and L. lactis MG1363 $\Delta d$ dtD. The MIC value for vancomycin was unchanged for all the strains investigated. Vancomycin resistance has been shown to be caused by a decrease in the degree of cross-linking (resulting in an increase in free D-Ala-D-Ala termini) together with a thicker cell wall (Cui et al., 2000). This implies that the total amount of free D-Ala-D-Ala termini present in the cell wall does not change significantly with the level of resistance to nisin.

\section{Vancomycin and nisin bind at or close to cell- division sites in L. lactis}

The total lipid II content in the Gram-positive bacterial cytoplasmic membrane is not correlated with nisin sensitivity (Kramer et al., 2004). Possible changes in the subcellular location of lipid II in the cytoplasmic membrane of $L$. lactis wild-type and $\mathrm{Nis}^{\mathrm{R}}$ strains were investigated, using direct binding of carboxyfluoresceinlabelled vancomycin (Daniel \& Errington, 2003). This was done to determine whether the binding pattern of nisin to lipid II is altered in the $\mathrm{Nis}^{\mathrm{R}}$ strain. As described above, vancomycin not only binds to the lipid II precursor, but also binds to D-Ala-D-Ala termini present in the peptidoglycan. Thus, as well as localizing lipid II and native peptidoglycan (Daniel \& Errington, 2003), carboxyfluorescein-labelled vancomycin will stain other parts of the cell wall. Approximately equal amounts of vancomycin were bound to wild-type L. lactis, L. lactis $\mathrm{Nis}{ }^{\mathrm{R}}$ and $L$. lactis $\Delta d l t D$ (Fig. 1a), indicating that the lipid II content in the cytoplasmic membrane is similar in all three strains. As described for S. pneumoniae (Daniel \& Errington, 2003), vancomycin was predominantly present at the celldivision sites in all three strains of L. lactis (Fig. 1a). Approximately equal amounts of vancomycin were bound at newly formed cell-division sites in L. lactis $\Delta d l t D$, compared to wild-type $L$. lactis and $L$. lactis $\mathrm{Nis}^{\mathrm{R}}$ cells (Fig. 1a).

A quite different pattern was observed for binding of carboxyfluorescein-labelled nisin to lipid II in the cytoplasmic membranes of $L$. lactis wild-type, $\mathrm{Nis}^{\mathrm{R}}$ and $\Delta d l t D$ cells. In this case, asymmetric fluorescent patches were visible in the bacterial membrane (Fig. 1b). In sensitive cells, the nisin-lipid II patches were located near possible (new) cell-division sites. These patches were also observed in the rod-shaped Bacillus subtilis, where lipid II is abducted from its original location to form nisin-lipid II patches (Hasper et al., 2006). Substantially less nisin was bound to cells of $L$. lactis $\mathrm{Nis}^{\mathrm{R}}$ than to cells of its parent, although the binding pattern was basically identical to that observed in the parent strain (Fig. 1b). This raises the question as to which characteristics of the cell wall might cause decreased binding of nisin to the cellular membrane and lipid II. The binding pattern of $L$. lactis $\Delta d l t D$ was also essentially the same as that of the parent (Fig. 1b). 
(a)

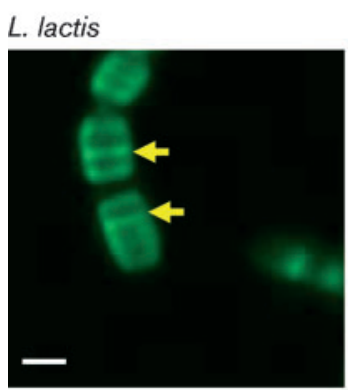

(b)

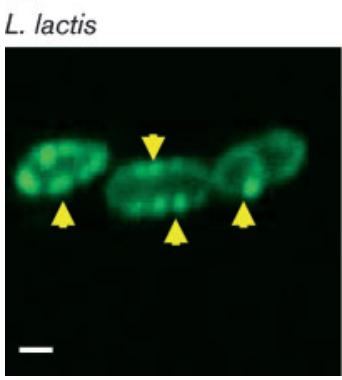

L. lactis $\mathrm{Nis}^{\mathrm{R}}$

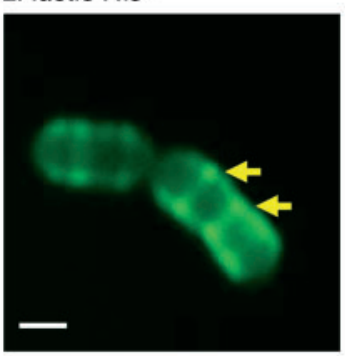

L. lactis $\mathrm{Nis}^{\mathrm{R}}$

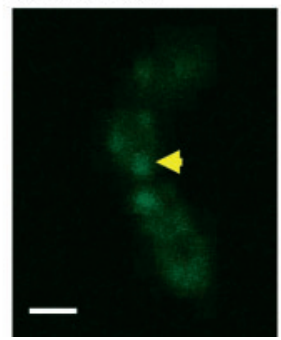

L. lactis $\Delta d l t D$

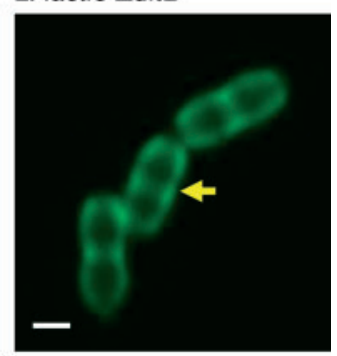

L. lactis $\Delta d l t D$

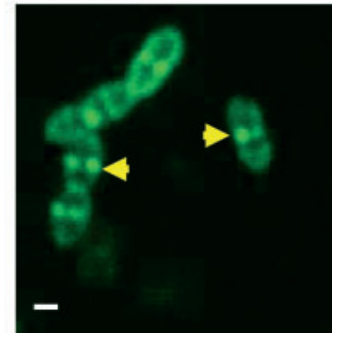

Fig. 1. Confocal microscopical examination of wild-type $L$. lactis, $L$. lactis $\mathrm{Nis}^{\mathrm{R}}$ and $L$. lactis $\Delta d l t D$ cells labelled with vancomycin (a) and nisin (b). The cells were incubated with $1 \mathrm{ml}$ fluorescein-labelled vancomycin $\mathrm{I}^{-1}$ or with $0.2 \mathrm{mg}$ fluorescein-labelled nisin $\mathrm{I}^{-1}$, as described in Methods. Representative cells are shown in each case. (a) Arrows represent lipid II-vancomycin binding in the cell-division site. (b) Arrows represent nisin-lipid II complexes formed near the cell-division site. Bars, $2 \mu \mathrm{m}$.

\section{The cell wall in L. lactis $\mathrm{Nis}^{\mathrm{R}}$ is thickened at the cell-division site}

Since the nisin-lipid II patches appear to be formed near the (future) cell-division sites (see Fig. 1a), this suggests that L. lactis is most sensitive to nisin at this location. In the $\mathrm{Nis}^{\mathrm{R}}$ strain, the acquisition of nisin resistance could be associated with molecular and/or structural changes in the cell wall. Since earlier studies have reported that nisin resistance in Listeria innocua is accompanied by an increased overall thickness of the peptidoglycan (Maisnier-Patin \& Richard, 1996), the cell walls of L. lactis and the $\mathrm{Nis}^{\mathrm{R}}$ derivative were examined by electron microscopy (Fig. 2a, b). The overall cell-wall thickness was $17 \pm 2 \mathrm{~nm}$, as measured in 10 different cells, in both the $\mathrm{Nis}^{\mathrm{R}}$ and the parental strains. Notably, a dramatic difference in thickness of the peptidoglycan was observed specifically at the cell-division sites: the cell-division site of L. lactis $\mathrm{Nis}^{\mathrm{R}}(11 \pm 2 \mathrm{~nm})$ was at least twice as thick as that of L. lactis $(5 \pm 2 \mathrm{~nm})$. Thus, upon the acquisition of nisin resistance, the cell wall of $L$. lactis $\mathrm{Nis}^{\mathrm{R}}$ thickens at the sites where lipid II is primarily located in the cell.

\section{LTA is less negatively charged in L. lactis Nis $^{R}$}

The fact that $L$. lactis $\Delta d l t D$ is more sensitive to nisin than its parent suggests that LTAs play an important role in the acquired nisin resistance mechanism. LTA was isolated from L. lactis, L. lactis $\mathrm{Nis}^{\mathrm{R}}$ and L. lactis $\Delta d l t D$, purified by FPLC and analysed by NMR spectroscopy. The NMR spectra show the resonance signal intensities of the Dalanine, galactose, glycerol and fatty acid fractions of the purified LTAs, which allows quantification of the substituents and to determine the mean glycerophosphate chain length (Morath et al., 2001). LTA of L. lactis $\mathrm{Nis}^{\mathrm{R}}$ contains more D-alanyl esters and more galactose than the parent strain (Table 1), and the backbone length is shortened in L. lactis $\mathrm{Nis}^{\mathrm{R}}$. LTA of L. lactis $\Delta d l t D$ contains almost no D-alanine, but exhibits a fourfold increase in galactose substitution relative to the wild-type strain. In conclusion, LTA of L. lactis $\mathrm{Nis}^{\mathrm{R}}$ is shorter in length and contains more $\mathrm{D}$-alanine and galactose than its sensitive counterparts, making the cell-wall barrier less negatively charged.

\section{DISCUSSION}

Lipid II is the docking molecule for the lantibiotic nisin (Breukink et al., 1999). We have shown previously that the lipid II content in the bacterial cytoplasmic membrane is not directly correlated with nisin sensitivity of the bacterium (Kramer et al., 2004). At least three mechanisms for nisin resistance in bacteria can be envisaged. First, an increase in the turnover of the sugar moieties to form peptidoglycan may take place, which would decrease the possibility of nisin binding to lipid II. Second, other molecules in the cytoplasmic membrane may prevent nisin from binding to the lipid II molecule. Third, nisin could be prevented from reaching the cytoplasmic membrane, and thus lipid II, due to changes in the cell wall such as an increase in thickness and/or a change in overall charge. A difference in charge would not affect sensitivity of the bacterium to vancomycin, since vancomycin is uncharged.

Earlier studies indicated that genes involved in cell-wall synthesis were involved in the acquisition of nisin resistance (Kramer et al., 2006). Furthermore, it is possible that changes in the subcellular location of the lipid II molecule make cells less susceptible to nisin. The location 
(a)
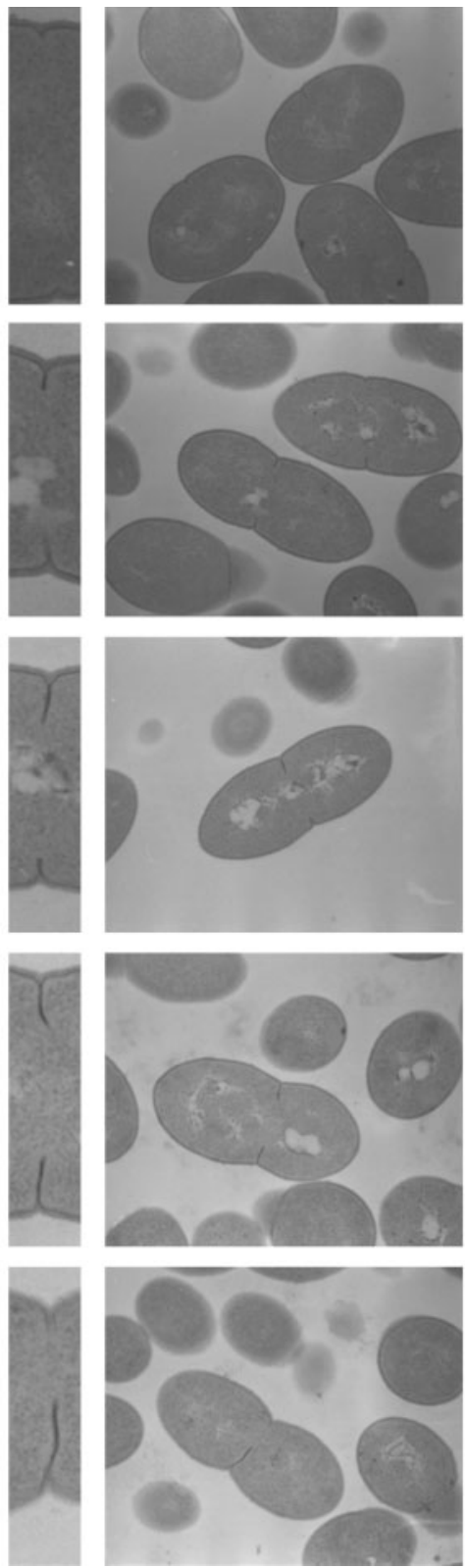

(b)
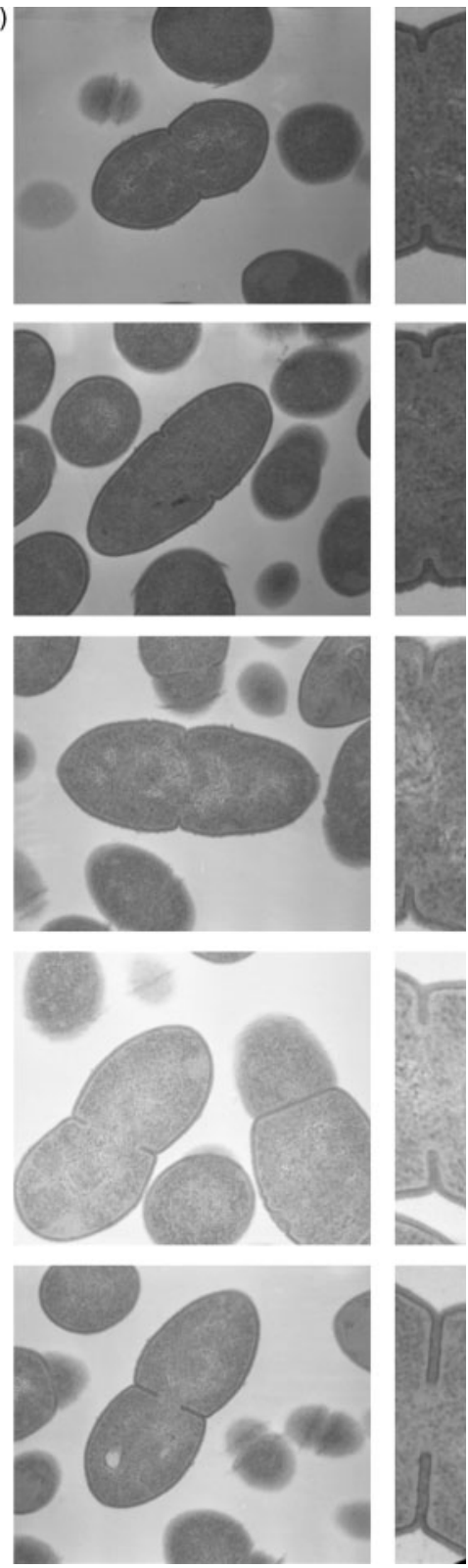

Fig. 2. Electron microscopic analysis of $L$. lactis (a) and L. lactis $\mathrm{Nis}^{\mathrm{R}}$ (b). Representative cells are shown. The overall cell-wall thickness is $17 \mathrm{~nm}$ in both strains. The thickened septa in the $\mathrm{Nis}^{\mathrm{R}}$ strains are clearly visible at different stages of division in the enlarged images on the left (a) and the right (b). of lipid II in the cytoplasmic membrane was visualized using fluorescently labelled vancomycin, an antibiotic that binds to D-Ala-D-Ala termini present in peptidoglycan, and precursors thereof (such as lipid II). Fluorescently labelled vancomycin was mainly localized at the septum in L. lactis, L. lactis $\mathrm{Nis}^{\mathrm{R}}$ and L. lactis $\Delta d l t D$. This result shows that the cell-wall synthesis machinery, including lipid II, is located at the cell-division sites in L. lactis, as also observed in the coccoid S. pneumoniae, as well as in the rod-shaped bacteria B. subtilis (Daniel \& Errington, 2003; Hasper et al., 2006) and Bacillus megaterium (Hasper et al., 2006).

Binding studies with fluorescently labelled nisin show that L. lactis $\mathrm{Nis}^{\mathrm{R}}$ binds significantly less nisin than L. lactis, whereas the binding pattern seems to be the same. In contrast to vancomycin binding, nisin and lipid II appear to form large complexes, which are visible as patches close to cell-division sites in the fluorescent images, rather than being distributed over the entire cell-division site. Abduction of lipid II and formation of giant complexes was also observed with fluorescently labelled nisin in $B$. subtilis and $B$. megaterium and with giant unilamellar vesicles containing lipid II (Hasper et al., 2006).

To determine how L. lactis $\mathrm{Nis}^{\mathrm{R}}$ is able to shield the cytoplasmic membrane and lipid II from nisin attack, the cell wall was examined in L. lactis wild-type and its $\mathrm{Nis}^{\mathrm{R}}$ derivative by electron microscopy. A locally thickened cell wall at the septum was observed. In L. lactis $\mathrm{Nis}^{\mathrm{R}}$, this is the primary location of lipid II in the cell. Thickening of the peptidoglycan was also observed at possible future celldivision sites. Localized thickening of the cell wall can be 
Table 1. Substitutions in LTA of L. lactis strains

LTA was isolated from L. lactis, L. lactis $\mathrm{Nis}^{\mathrm{R}}$ and L. lactis $\Delta$ dltD, purified by FLPC and analysed by NMR spectroscopy, as described in Methods. The NMR spectra (see Fig. S1, available with the online version of this paper) were used to quantify the substituents in relation to the phosphate content and to determine the mean glycerophosphate chain length.

\begin{tabular}{|lcccr|}
\hline Strain & Galactose in LTA (\%) & D-Alanine in LTA (\%) & Non-substituted LTA (\%) & Backbone length \\
\hline L. lactis IL1403 & $11.8 \pm 1.6$ & $28.5 \pm 6.6$ & $59.8 \pm 5.2$ & 16 \\
L. lactis IL1403 Nis ${ }^{\mathrm{R}}$ & $25.0 \pm 5.2$ & $45.0 \pm 6.0$ & $30.0 \pm 1.8$ & 7 \\
L. lactis MG1363 $\Delta$ dltD & $46.0 \pm 0.4$ & $5.9 \pm 3.5$ & $48.0 \pm 3.3$ & 12 \\
\hline
\end{tabular}

the result of an increased turnover of the lipid II headgroup. This would decrease the lifetime of lipid II and reduce the amount of binding of nisin to lipid II. An increased turnover of sugar moieties in the lipid II molecule could be due to a higher expression of certain penicillin-binding proteins (PBPs), which are involved in peptidoglycan chain cross-linking and strand elongation (van Heijenoort, 2001). Indeed, in L. lactis $\mathrm{Nis}^{\mathrm{R}}$, expression of a gene encoding PBP2A is increased relative to L. lactis (Kramer et al., 2006). A putative PBP has also been shown to be more highly expressed in a Nis ${ }^{\mathrm{R}}$ strain of Listeria monocytogenes (Gravesen et al., 2001). It has also been observed that PBP1A plays an essential role in resistance to cationic antimicrobial peptides in group B Streptococcus (Hamilton et al., 2006). However, it was not established whether the cell wall was (locally) thickened. Alternatively, nisin could be less effective in abducting lipid II molecules to form patches in the $\mathrm{Nis}^{\mathrm{R}}$ strain because of the lower accessibility to lipid II due to the thickened peptidoglycan at the septa. The observed localized thickening of the cell wall at only the septa in L. lactis $\mathrm{Nis}^{\mathrm{R}}$ is in contrast with observations in Listeria innocua, where the entire cell wall is thicker in a Nis ${ }^{\mathrm{R}}$ strain (Maisnier-Patin \& Richard, 1996). Listeria innocua is a fairly nisin-insensitive bacterium and it is therefore difficult to use this species in a comparison of resistance development in $L$. lactis, since $L$. lactis is very sensitive to nisin. Thickening of the entire cell wall could be a last resort for Listeria innocua to protect itself from the action of nisin. Recently, it was reported that immediate lethal doses of nisin caused membrane permeabilization, followed by accelerated cell division, cell-envelope biosynthesis inhibition and aberrant cell morphogenesis in $B$. subtilis (Hyde et al., 2006). This is in line with our findings that resistant strains appear to behave in the opposite way: the cell division time for the $\mathrm{Nis}^{\mathrm{R}}$ strain is longer than in the wild-type strain, which indicates slower cell division (data not shown), thereby making lipid II less accessible.

LTA is the major determinant of cell-wall electrostatic interactions, because it is predominantly negatively charged. In addition, it can contain positively charged Dalanyl esters. A large difference was observed between the LTA of L. lactis and that of L. lactis $\mathrm{Nis}^{\mathrm{R}}$ : the latter contains many more D-alanyl esters and more galactose. This is in accordance with transcriptome analysis data, showing higher expression of genes of the dlt and gal operons
(Kramer et al., 2006), and is also in accordance with data from a strain of Staphylococcus aureus containing several copies of the $d l t$ operon. The dlt operon is responsible for D-alanyl ester substitution in LTA, leading to the incorporation of positive charges. The Staphylococcus aureus strain with increased $d l t$ operon expression was less sensitive to various antimicrobial peptides, including nisin (Peschel et al., 1999). Nisin has a net positive charge and the increase of positive charge in the cell wall probably hampers nisin from reaching lipid II in the cytoplasmic membrane by electrostatic repulsion. In a Lactobacillus plantarum strain, LTA showed higher levels of glucose when the dlt operon was deleted (Palumbo et al., 2006). This suggests that by deleting the dlt operon, other sugar moieties increase in number in the LTA. It has also been described in several studies that deletion of dltA in Enterococcus faecalis and Streptococcus pneumoniae, resulting in the absence of D-alanine in the teichoic acids, produces a strain that is more sensitive to antimicrobial peptides (Kovacs et al., 2006; Fabretti et al., 2006). However, these strains are less sensitive to nisin than $L$. lactis. It has been suggested that many low-G + C Grampositive bacteria have teichoic acids that contain D-alanine residues in order to protect themselves from the action of antimicrobials such as nisin (Kovacs et al., 2006). An increase in substituted LTA might make the cell wall more tightly packed, thereby shielding the membrane and lipid II from nisin binding. It is also interesting to note that the backbone length of LTA is significantly reduced in L. lactis $\mathrm{Nis}^{\mathrm{R}}$, which could affect cell-wall packing density. In contrast to LTA of $\mathrm{Nis}^{\mathrm{R}}$ Streptococcus bovis, L. lactis $\mathrm{Nis}^{\mathrm{R}}$ cells did not contain more LTA (Mantovani \& Russell, 2001), since the same amount of LTA was purified from wild-type cells as from L. lactis $\mathrm{Nis}^{\mathrm{R}}$ cells. The observed increased sensitivity of $L$. lactis $\Delta d l t D$ can therefore be attributed to an increase in negative charge in the LTA, which might lead to a more efficient passage of nisin through the cell wall to reach lipid II and form pores. The acquired $\mathrm{Nis}^{\mathrm{R}}$ phenotype observed in L. lactis is most probably a combination of at least two main effects that add up to a final high nisin resistance level. Shielding of lipid II by the cell wall is acquired by changing the overall charge of LTA. The reduction in accessibility is also accomplished by local thickening of the cell wall at the celldivision sites, where lipid II is most abundant. Shielding of the membrane, and thus the lipid II molecule, appears to 
be the major defence mechanism of L. lactis IL1403 against nisin.

\section{ACKNOWLEDGEMENTS}

We gratefully acknowledge Leo Cobianchi and Klaas Sjollema for the excellent technical assistance in LTA isolation and electron microscopy of L. lactis. This work was supported by the NWO and STW grant 3495257. Project title: Lipid II, the target for the lantibiotic nisin.

\section{REFERENCES}

Breukink, E., Wiedemann, I., van Kraaij, C., Kuipers, O. P., Sahl, H.-G. \& de Kruijff, B. (1999). Use of the cell wall precursor lipid II by a pore-forming peptide antibiotic. Science 286, 2361-2364.

Brötz, H., Josten, M., Wiedemann, I., Schneider, U., Götz, F., Bierbaum, G. \& Sahl, H.-G. (1998). Role of lipid-bound peptidoglycan precursors in the formation of pores by nisin, epidermin and other lantibiotics. Mol Microbiol 30, 317-327.

Chopin, A., Chopin, M. C., Moillo-Batt, A. \& Langella, P. (1984). Two plasmid-determined restriction and modification systems in Streptococcus lactis. Plasmid 11, 260-263.

Courtin, P., Miranda, G., Guillot, A., Wessner, F., Mezange, C., Domakova, E., Kulakauskas, S. \& Chapot-Chartier, M. P. (2006). Peptidoglycan structure analysis of Lactococcus lactis reveals the presence of an L,D-carboxypeptidase involved in peptidoglycan maturation. J Bacteriol 188, 5293-5298.

Cui, L., Murakami, H., Kuwahara-Arai, K., Hanaki, H. \& Hiramatsu, K. (2000). Contribution of a thickened cell wall and its glutamine nonamidated component to the vancomycin resistance expressed by Staphylococcus aureus Mu50. Antimicrob Agents Chemother 44, 2276-2285.

Daniel, R. A. \& Errington, J. (2003). Control of cell morphogenesis in bacteria: two distinct ways to make a rod-shaped cell. Cell 113, 767-776.

Delcour, J., Ferrain, T., Deghorian, M., Palumbo, E. \& Hols, P. (1999). The biosynthesis and functionality of the cell wall of lactic acid bacteria. Antonie Van Leeuwenhoek 76, 159-184.

Delves-Broughton, J., Blackburn, P., Evans, R. J. \& Hugenholtz, J. (1996). Applications of the bacteriocin, nisin. Antonie van Leeuwenhoek 69, 193-202.

Duwat, P., Cochu, A., Ehrlich, S. D. \& Gruss, A. (1997). Characterization of Lactococcus lactis UV-sensitive mutants obtained by ISS1 transposition. J Bacteriol 179, 4473-4479.

Fabretti, F., Theilacker, C., Baldassarri, L., Kaczynski, Z., Kropec, A., Holst, O. \& Huebner, J. (2006). Alanine esters of enterococcal lipoteichoic acid play a role in biofilm formation and resistance to antimicrobial peptides. Infect Immun 74, 4164-4171.

Gravesen, A., Sorensen, K., Aarestrup, F. M. \& Knochel, S. (2001). Spontaneous nisin-resistant Listeria monocytogenes mutants with increased expression of a putative penicillin-binding protein and their sensitivity to various antibiotics. Microb Drug Resist 7, 127-135.

Grossiord, B. P., Luesink, E. J., Vaughan, E. E., Arnaud, A. \& de Vos, W. M. (2003). Characterization, expression and mutation of the Lactococcus lactis galPMKTE genes, involved in the galactose utilization via the Leloir pathway. J Bacteriol 185, 870-878.

Hamilton, A., Popham, D. L., Carl, D. J., Lauth, X., Nizet, V. \& Jones, A. L. (2006). Penicillin-binding protein 1a promotes resistance of group B streptococcus to antimicrobial peptides. Infect Immun 74, 6179-6187.

Hasper, H. E., de Kruijff, B. \& Breukink, E. (2004). Assembly and stability of nisin-lipid II pores. Biochemistry 43, 11567-11575.
Hasper, H. E., Kramer, N. E., Smith, J. L., Hillman, L. D., Zachariah, C., Kuipers, O. P., de Kruijff, B. \& Breukink, E. (2006). An alternative bactericidal mechanism of action for lantibiotic peptides that target lipid II. Science 313, 1636-1637.

Heaton, M. P. \& Neuhaus, F. C. (1993). The significance of secondary cell wall polymers in Gram-positive organisms: Lactobacillus casei as a model for study of D-alanyl-teichoic acid biosynthesis and function. In The Lactic Acid Bacteria, pp. 89-98. Edited by E. L. Foo, H. G. Griffin, R. Mollby \& C. G. Heden. Wymondham: Horizon.

Hurst, A. (1981). Nisin. Adv Appl Microbiol 27, 85-123.

Hyde, A. J., Parisot, J., McNichol, A. \& Bonev, B. B. (2006). Nisininduced changes in Bacillus morphology suggest a paradigm of antibiotic action. Proc Natl Acad Sci U S A 103, 19896-19901.

Jung, G. (1991). Lantibiotics: a survey. In Lantibiotics: a Survey, pp. 1-34. Edited by H.-G. Sahl \& G. Jung. Amsterdam, The Netherlands: ESCOM Science Publishers.

Kovacs, M., Halfman, A., Fedtke, I., Heintz, M., Peschel, A., Vollmer, W., Hakenbeck, R. \& Bruckner, R. (2006). A functional dlt operon, encoding proteins required for incorporation of $\mathrm{D}$-alanine in teichoic acids in Gram-positive bacteria confers resistance to cationic peptides in Streptococcus pneumoniae. J Bacteriol 188, 5797-5805.

Kramer, N. E., Smid, E. J., Kok, J., de Kruijff, B., Kuipers, O. P. \& Breukink, E. (2004). Sensitivity or resistance of Gram-positive bacteria to nisin is not determined by the amount of the receptor Lipid II. FEMS Microbiol Lett 239, 157-161.

Kramer, N. E., Hijum, S. A. F. T., Knol, J., Kok, J. \& Kuipers, O. P. (2006). Identification by DNA-microarrays of genes involved in acquired resistance against nisin in Lactococcus lactis. Antimicrob Agents Chemother 50, 1753-1762.

Maisnier-Patin, S. \& Richard, J. (1996). Cell wall changes in nisinresistant variants of Listeria innocua grown in the presence of high nisin concentrations. FEMS Microbiol Lett 140, 29-35.

Mantovani, H. C. \& Russell, J. B. (2001). Nisin resistance of Streptococcus bovis. Appl Environ Microbiol 67, 808-813.

Mattick, A. T. \& Hirsch, A. (1944). A powerful inhibitory substance produced by group N streptococci. Nature 154, 551.

Morath, S., Geyer, A. \& Hartung, T. (2001). Structure-function relationship of cytokine induction by lipoteichoic acid from Staphylococcus aureus. J Exp Med 193, 393-397.

Naumova, I. B., Shashkov, A. S., Tul'skaya, E. M., Streshinskaya, G. M., Kozlova, Y. I., Potekhina, N. V., Evtushenko, L. I. \& Stackebrandt, E. (2001). Cell wall teichoic acids: structural diversity, species specificity in the genus Nocardiopsis, and chemotaxonomic perspective. FEMS Microbiol Rev 25, 269-283.

Palumbo, E., Deghorian, M., Cocconcelli, P. S., Kleerebezem, M., Geyer, A., Hartung, T., Morath, S. \& Hols, P. (2006). D-Alanyl ester depletion of teichoic acids in Lactobacillus plantarum results in a major modification of lipoteichoic acid composition and cell wall perforations at the septum mediated by the Acm 2 autolysin. J Bacteriol 188, 3709-3715.

Peschel, A., Otto, M., Jack, R. W., Kalbacher, H., Jung, G. \& Götz, F. (1999). Inactivation of the dlt operon in Staphylococcus aureus confers sensitivity to defensins, protegrins and other antimicrobial peptides. $J$ Biol Chem 274, 8405-8410.

Pol, I. E. \& Smid, E. J. (1999). Combined action of nisin and carvacrol on Bacillus cereus and Listeria monocytogenes. Lett Appl Microbiol 29, 166-170.

Rouser, G., Fleisher, S. \& Yamamoto, A. (1970). Two dimensional thin layer chromatographic separation of polar lipids and determination of phospholipids by phosphorus analysis of spots. Lipids $\mathbf{5}$, 494-496. 
Sahl, H. G. \& Bierbaum, G. (1998). Lantibiotics: biosynthesis and biological activities of uniquely modified peptides from Grampositive bacteria. Annu Rev Microbiol 52, 41-79.

Sheldrick, G. M., Jones, P. G., Kennard, O., Williams, D. H. \& Smith, G. A. (1978). Structure of vancomycin and its complex with acetyl-Dalanyl-D-alanine. Nature 271, 223-225.

Steen, A., Buist, G., Leenhouts, K. J., El, K. M., Grijpstra, F., Zomer, A. L., Venema, G., Kuipers, O. P. \& Kok, J. (2003). Cell wall attachment of a widely distributed peptidoglycan binding domain is hindered by cell wall constituents. J Biol Chem 278, 23874-23881.

Terzaghi, B. E. \& Sandine, W. E. (1975). Improved medium for lactic streptococci and their bacteriophages. Appl Microbiol 29, 807-813.

van Heijenoort, J. (2001). Formation of the glycan chains in the synthesis of bacterial peptidoglycan. Glycobiology 11, 25R-36R.

Edited by: D. A. Mills 